\title{
Point-of-Care Thoracic Ultrasonography in Patients With Cirrhosis and Liver Failure
}

Kamal Kajal ${ }^{1}$, Madhumita Premkumar ${ }^{2}$, Sreedhara B. Chaluvashetty ${ }^{3}$, Harish Bhujade ${ }^{3}$, Anand V. Kulkarni 4

1. Anesthesia and Critical Care, Post Graduate Institute of Medical Education \& Research, Chandigarh, IND 2. Hepatology, Post Graduate Institute of Medical Education \& Research, Chandigarh, IND 3. Radiodiagnosis, Post Graduate Institute of Medical Education \& Research, Chandigarh, IND 4. Hepatology, Asian Institute of Gastroenterology, Hyderabad, IND

Corresponding author: Madhumita Premkumar, drmadhumitap@gmail.com

\begin{abstract}
Point-of-care ultrasonography (POCUS) helps determine liver-related pathologies like an abscess, portal vein or hepatic vein thromboses, presence of ascites, site for pleural or ascitic paracentesis, and guiding biopsies. POCUS is revolutionizing the management of critically ill patients presenting with pneumonia, acute respiratory distress syndrome, acute-on-chronic liver failure, and in the emergency. The objectives of thoracic ultrasonography (TUS) are to aid the clinician in differentiating between pneumonia, effusions, interstitial edema and collections, and in estimating the volume status of patients with liver disease using inferior vena cava dynamic indices. The use of POCUS in patients with cirrhosis has since evolved. It is now widely used to help diagnose volume status, left ventricular diastolic dysfunction, myocardial infarction, and right ventricular dilation due to pulmonary embolism and to determine the causes for weaning failures such as effusions, lung collapse, and pneumothorax. During the Coronavirus Disease 2019 (COVID-19) pandemic, moving patients for computed tomography can be difficult. Therefore, TUS is now essential in liver transplantation and intensive care practice to assess ventilatory pressures, cardiac function, and fluid management. This review indicates the current and optimized use of TUS, offers a practical guide on TUS in the liver intensive care unit (ICU), and presents a diagnostic pathway for determining lung and pleural pathology, resolution of respiratory failure, and aid weaning from mechanical ventilation.
\end{abstract}

Review began 04/06/2021 Review ended 06/08/2021 Published 06/10/2021

(c) Copyright 2021

Kajal et al. This is an open access article distributed under the terms of the Creative Commons Attribution License CC-BY 4.0., which permits unrestricted use, distribution, and reproduction in any medium, provided the original author and source are credited.
Categories: Anesthesiology, Emergency Medicine, Gastroenterology

Keywords: liver transplantation, lung ultrasound, point-of-care, pocus, cirrhosis, intensive care, pneumonia

\section{Introduction And Background}

Thoracic ultrasonography (TUS) of the lung and pleura is a key component of critical care point of care ultrasonography (POCUS) in patients with cirrhosis, acute-on-chronic liver failure (ACLF), and those with hepatic hydrothorax [1]. In critically ill patients with cirrhosis, TUS can be used to diagnose patients with undifferentiated dyspnea [2], suspected pneumothorax [3], hemothorax, pneumonia [4,5], lung collapse [6], ventilator-associated pneumonia [7], titration of positive end-expiratory pressure in acute respiratory distress syndrome (ARDS) [6,7], weaning failure [8,9], and pulmonary embolism [10]. POCUS can be performed by clinicians using inexpensive handheld machines, whereas consultative ultrasonography is performed by radiologists in a suite with expensive and advanced ultrasound machines. The main indications for performing a combination of POCUS, TUS, and transthoracic echocardiography (TTE) are to improve bedside diagnosis of pulmonary diseases and hemodynamic status in patients with liver disease which facilitates clinical decision pathways in intensive care units (ICUs) [8], operating rooms, or emergency department (Table 1) [2-11]. 


\section{Cureus}

\begin{tabular}{|c|c|c|}
\hline Condition & Differential & Clinical Decision Making \\
\hline Chest pain [4] & $\begin{array}{l}\text { Myocardial infarction, } \\
\text { myocarditis, pulmonary } \\
\text { embolism }\end{array}$ & Cardiac comorbidities are well described in cirrhosis and need definitive treatment \\
\hline Dyspnea [2] & $\begin{array}{l}\text { Pneumonia, lung } \\
\text { collapse, pneumothorax, } \\
\text { hepato-pulmonary } \\
\text { syndrome }\end{array}$ & $\begin{array}{l}\text { Undifferentiated dyspnea can be diagnosed using TUS. Hepatopulmonary syndrome } \\
\text { (HPS) requires screening using saline contrast echocardiography which can be done } \\
\text { at the bedside with a phased array probe. }\end{array}$ \\
\hline Hypoxia & $\begin{array}{l}\text { Pneumonia, acute } \\
\text { respiratory distress } \\
\text { syndrome (ARDS) }\end{array}$ & Relevant in patients with liver disease with sepsis and pancreatitis \\
\hline Shock & $\begin{array}{l}\text { Dehydration, over } \\
\text { diuresis, myocardial } \\
\text { infarction }\end{array}$ & $\begin{array}{l}\text { Determine volume resuscitation in cirrhosis using inferior vena cava (IVC) } \\
\text { collapsibility and rule out cardiogenic causes. The use of central venous pressure } \\
\text { (CVP) in cirrhosis is less reliable for guiding fluids in critical illness. }\end{array}$ \\
\hline Pleurisy & $\begin{array}{l}\text { Pulmonary embolism, } \\
\text { pneumothorax, post- } \\
\text { biopsy pain }\end{array}$ & $\begin{array}{l}\text { Pleuritic pain can be due to acute pulmonary embolism. Since cirrhosis is a } \\
\text { procoagulant state, pulmonary embolism is not uncommon in critically ill patients } \\
\text { with cirrhosis. }\end{array}$ \\
\hline Thoracic trauma & Hemothorax & Blunt trauma or road traffic accidents \\
\hline ARDS $[2,6]$ & $\begin{array}{l}\text { Interstitial edema, } \\
\text { collapse of lung, } \\
\text { pancreatitis }\end{array}$ & $\begin{array}{l}\text { Respiratory failure diagnosis, ventilatory settings modification. Differentiation } \\
\text { between pneumonia, lung collapse, and effusion using LUS is useful to guide } \\
\text { ventilatory settings in cirrhosis and acute-on-chronic liver failure (ACLF) }\end{array}$ \\
\hline $\begin{array}{l}\text { Pulmonary } \\
\text { thromboembolism } \\
\text { [9] }\end{array}$ & Pneumonia & $\begin{array}{l}\text { Anticoagulation can be started at the bedside in case of the diagnostic right- } \\
\text { atrial/right-ventricular collapse seen on bedside echocardiography. }\end{array}$ \\
\hline $\begin{array}{l}\text { Identify right main } \\
\text { stem bronchus } \\
\text { intubation }\end{array}$ & $\begin{array}{l}\text { The selective intubation } \\
\text { of a lung segment can be } \\
\text { assessed }\end{array}$ & Tube placement in mechanical ventilation \\
\hline \multirow{4}{*}{$\begin{array}{l}\text { Ultrasound- } \\
\text { guided } \\
\text { interventions [10] }\end{array}$} & Central line placement & Pneumothorax/hemothorax after line placement \\
\hline & Biopsy & $\begin{array}{l}\text { A liver biopsy can be done at the bedside. Ultrasound-guided fine-needle aspiration } \\
\text { can be done from suspicious lesions. }\end{array}$ \\
\hline & Thoracentesis & $\begin{array}{l}\text { Diagnostic or Therapeutic thoracentesis can be done with percutaneous drain } \\
\text { placement at the bedside. }\end{array}$ \\
\hline & $\begin{array}{l}\text { Drainage of amebic liver } \\
\text { abscess }\end{array}$ & Single time aspiration or drain placement \\
\hline
\end{tabular}

TABLE 1: Indications for thoracic ultrasonography (TUS) in patients with cirrhosis

[2-11]

Abbreviations: ARDS, acute respiratory distress syndrome; TUS, thoracic ultrasonography; IVC, inferior vena cava; LUS, lung ultrasound

This is now of paramount importance in the Coronavirus Disease 2019 (COVID-19) era, as moving patients to radiology units for computed tomography or radiographs is difficult and more clinicians, including hepatologists and gastroenterologists, should learn the skill of a fast POCUS of the lung, heart, and abdomen [12]. There are restrictions on the movement of healthcare personnel to ICUs across all specialties. We have already reported the effect of COVID-19 on liver biochemistries [13]. Now, it is increasingly important that ICUs and liver transplantation units become self-reliant in bedside diagnosis of pulmonary pathology by performing a simple TUS. The use of 'telemedicine' tools can also aid expert radiologists in reviewing the real-time images obtained by the primary physician in the ICU. The POCUS performed at the bedside can be interpreted remotely by an experienced radiologist; this has enabled early and appropriate decisions, especially in COVID-19 units. The concept is now adopted across other ICUs to minimize healthcare worker and patient movement [14]. 


\section{Review}

\section{Equipment required for TUS in patients with liver disease}

A wide variety of scanning equipment can be used for bedside pleural ultrasonography and associated procedures in patients with cirrhosis and liver failure. In patients with liver disease, modification of scanning technique needs to be done due to the presence of ascites and limited scanning window. In such critically ill cirrhotic patients, the use of TUS can guide critical care decisions such as end points of fluid resuscitation, lung recruitment maneuvers, adjustment of pressure settings on mechanical ventilation, monitoring pneumonia, and detection of pneumothorax $[9,10]$.

\section{Transducers}

The TUS is best done using either the curvilinear transducer (1-5 MHz), which is useful for imaging the base of the lung, costophrenic angles, pleural surface, and lower intercostal spaces as it has a large footprint. Once the pathology is identified, the clinician can switch to a linear probe. This high-frequency probe can image up to a depth of $4 \mathrm{~cm}$ with high resolution and is used to see the A-lines and B-lines. However, only a small imaging footprint is available, albeit in high resolution. Therefore a 1-3 MHz phased array probe can also be used for TUS and can be used to scan with ease in the intercostal spaces. The phased array probe is also used for complimentary echocardiography done at the bedside. The phased array probe is useful for imaging more diffuse lung and pleural pathology. This probe also has enough tissue penetration depth to image structures deep within the thorax, unlike the linear high-frequency probe. This is the best probe for assessing lung sliding, identification of pleural lines, and procedural guidance $[15,16]$.

POCUS is now accepted in critical care practice worldwide and has gained increased acceptance in hepatology and liver transplantation practice. Usually, we begin with a POCUS of the abdomen and move to the lung bases with the curvilinear probe with an abdominal preset. The lung is scanned using the abdominal preset, but the lung preset should be used for anterior views. The abdominal preset is useful for imaging solid lesions like consolidation. A depth of 9-14 cm should be chosen for anterior views. Then, the transducer is switched to the linear probe with a lung preset, and the lung sliding is assessed and areas of interest identified. The lung ultrasound (LUS) score is calculated using the mapping technique described in a subsequent section. Lastly, we switch to a phased array probe to visualize specific areas like lung parenchyma and deeper structures. The phased array probe is then switched to a cardiac preset, and basic echocardiography is done to complete the POCUS examination relevant to the patients with a critical illness.

Gain or depth may need to be decreased to appreciate the hyperechoic pleural line clearly. We are required to view the intraabdominal organs (liver or spleen) and the diaphragmatic pleural reflection in dependent views. The pleura should be imaged by keeping the probe perpendicular to it. The operator should assess for lung sliding, presence of A- and B-lines, evidence of pleural effusion, consolidation of the underlying lung, and associated infra-diaphragmatic structures like the liver and the spleen in patients with liver disease.

Table 2 shows the normal findings and comparison of TUS with conventional computed tomography (CT) and radiographs [15-20].

\begin{tabular}{|c|c|c|c|c|c|}
\hline Condition & $\begin{array}{l}\text { Findings on } \\
\text { TUS }\end{array}$ & $\begin{array}{l}\text { Ultrasound } \\
\text { diagnosis }\end{array}$ & $\begin{array}{l}\text { Comparison with CT/ } \\
\text { Radiograph }\end{array}$ & Advantages & Differentials \\
\hline Normal & $\begin{array}{l}\text { An A-line } \\
\text { pattern with } \\
\text { lung sliding } \\
\text { indicates a } \\
\text { normal } \\
\text { aeration } \\
\text { pattern }\end{array}$ & $\begin{array}{l}\text { Lung sliding } \\
\text { present with A- } \\
\text { lines/ less than two } \\
\text { isolated B-lines }\end{array}$ & Bedside diagnosis & $\begin{array}{l}\text { More cost-efficient. No ionizing } \\
\text { radiation }\end{array}$ & $\begin{array}{l}\text { Lung sliding is } \\
\text { also seen in } \\
\text { breath-holding, } \\
\text { apnea in } \\
\text { endotracheal tube } \\
\text { displacement, or } \\
\text { pleurodesis. }\end{array}$ \\
\hline $\begin{array}{l}\text { Pneumothorax } \\
\text { [14] }\end{array}$ & $\begin{array}{l}\text { Loss of lung } \\
\text { sliding }\end{array}$ & $\begin{array}{l}\text { Loss of lung sliding } \\
\text { can also be seen } \\
\text { with pleurodesis or } \\
\text { breath-holding }\end{array}$ & $\begin{array}{l}\text { High PEEP, } \\
\text { COPD/emphysema, } \\
\text { mainstem intubation, } \\
\text { lung bullae, and } \\
\text { ventilator apnea may } \\
\text { also lead to loss of } \\
\text { lung sliding }\end{array}$ & Bedside drainage & $\begin{array}{l}\text { Presence of B- } \\
\text { lines and/or } \\
\text { pleural pulse } \\
\text { (transmitted } \\
\text { pleural movement } \\
\text { due to the heart) } \\
\text { also rules out } \\
\text { pneumothorax }\end{array}$ \\
\hline Pleural & $\begin{array}{l}\text { Anechoic area } \\
\text { surrounded by }\end{array}$ & & & $\begin{array}{l}\text { TUS is better for checking } \\
\text { pleural effusion septations, } \\
\text { differentiating pleural fluid from }\end{array}$ & Empyema, \\
\hline
\end{tabular}




\section{Cureus}

\begin{tabular}{|c|c|c|c|c|c|}
\hline $\begin{array}{l}\text { effusion/ } \\
\text { Hepatic } \\
\text { hydrothorax }\end{array}$ & $\begin{array}{l}\text { typical } \\
\text { anatomic } \\
\text { boundaries }\end{array}$ & $\begin{array}{l}\text { Fluid in pleural } \\
\text { cavity }\end{array}$ & $\begin{array}{l}\text { Sensitivity } 93 \% \text { versus } \\
47 \% \text { with CXR }\end{array}$ & $\begin{array}{l}\text { chest wall tumor invasion, } \\
\text { pleural thickening, and pleural } \\
\text { masses compared with chest } \\
\text { CT scan }\end{array}$ & $\begin{array}{l}\text { hemothorax, } \\
\text { pleural mass }\end{array}$ \\
\hline $\begin{array}{l}\text { Loculated } \\
\text { pleural } \\
\text { effusion }\end{array}$ & $\begin{array}{l}\text { Anechoic area } \\
\text { with } \\
\text { septations }\end{array}$ & $\begin{array}{l}\text { Loculated fluid in } \\
\text { pleural cavity; } \\
\text { suggests chronic } \\
\text { collection }\end{array}$ & $\begin{array}{l}\text { The sensitivity of } \\
\text { diagnosing a } \\
\text { complicated } \\
\text { parapneumonic } \\
\text { effusion using LUS, } \\
\text { chest radiography, and } \\
\text { CT was } 69 \%, 61 \% \text {, } \\
\text { and } 76 \% \text {, respectively. }\end{array}$ & $\begin{array}{l}\text { Pleural effusions can also } \\
\text { loculate because of adhesions. }\end{array}$ & $\begin{array}{l}\text { Hemothorax, } \\
\text { pyothorax, } \\
\text { chylothorax, or } \\
\text { tuberculous } \\
\text { pleuritis }\end{array}$ \\
\hline $\begin{array}{l}\text { Pulmonary } \\
\text { embolism [11] }\end{array}$ & $\begin{array}{l}\text { Peripheral } \\
\text { wedge- } \\
\text { shaped } \\
\text { abnormalities } \\
\text { or alternate } \\
\text { etiologies } \\
\text { (e.g., alveolar } \\
\text { consolidation) }\end{array}$ & $\begin{array}{l}\text { RV dilation, } \\
\text { ventricle size ratio, } \\
\text { abnormal septal } \\
\text { motion, TR, RV } \\
\text { hypokinesis, } \\
\text { pulmonary } \\
\text { hypertension, RV } \\
\text { end-diastolic } \\
\text { diameter }\end{array}$ & $\begin{array}{l}\text { McConnel Sign (RV } \\
\text { dysfunction with } \\
\text { characteristic sparing } \\
\text { of the apex) }\end{array}$ & $\begin{array}{l}\text { Early anticoagulation can be } \\
\text { offered. }\end{array}$ & $\begin{array}{l}\text { Pneumonia, lung } \\
\text { collapse }\end{array}$ \\
\hline $\begin{array}{l}\text { Pneumonia } \\
{[15]}\end{array}$ & $\begin{array}{l}\text { Subpleural } \\
\text { consolidations } \\
\text { and dynamic } \\
\text { air } \\
\text { bronchograms }\end{array}$ & Consolidation & $\begin{array}{l}\text { Sensitivity of } 0.82 \text { and } \\
\text { specificity of } 0.94 \text { for } \\
\text { consolidation when } \\
\text { compared to CT. } \\
\text { Sensitivity } 97 \text { vs. } 75 \% \\
\text { with CXR }\end{array}$ & $\begin{array}{l}\text { Resolution of pneumonia can } \\
\text { be tracked using TUS }\end{array}$ & $\begin{array}{l}\text { Lung collapse, } \\
\text { airway block } \\
\text { alveolar } \\
\text { hemorrhage }\end{array}$ \\
\hline ARDS [16] & $\begin{array}{l}\text { The presence } \\
\text { of B-lines } \\
\text { indicates an } \\
\text { alveolar or } \\
\text { interstitial } \\
\text { abnormality }\end{array}$ & Interstitial edema & $\begin{array}{l}\text { Sensitivity } 82-92 \% \\
\text { compared to CT }\end{array}$ & $\begin{array}{l}\text { Best when abnormal findings } \\
\text { reached the pleural surface }\end{array}$ & $\begin{array}{l}\text { Viral pneumonia, } \\
\text { pulmonary } \\
\text { embolism }\end{array}$ \\
\hline $\begin{array}{l}\text { Cardiogenic } \\
\text { pulmonary } \\
\text { edema }[17,18]\end{array}$ & $\begin{array}{l}\text { Profuse } \\
\text { bilateral B- } \\
\text { lines with } \\
\text { smooth } \\
\text { pleural } \\
\text { morphology }\end{array}$ & $\begin{array}{l}\text { Pulmonary artery } \\
\text { occlusion pressure } \\
\text { (PAOP) estimation } \\
\text { with TTE }\end{array}$ & $\begin{array}{l}\text { Sensitivity } 0.90 \text { and } \\
\text { Specificity } 0.93 \text { with } \\
\text { CT. Sensitivity } 95 \% \text { vs. } \\
55 \% \text { with CXR }\end{array}$ & $\begin{array}{l}\text { TUS that includes analysis of } \\
\text { A- and B-lines correlates with } \\
\text { the PAOP and may distinguish } \\
\text { patients with cardiogenic } \\
\text { pulmonary edema (elevated } \\
\text { PAOP) from those with acute } \\
\text { lung injury (normal PAOP) }\end{array}$ & $\begin{array}{l}\text { Interstitial } \\
\text { pneumonia, ARDS }\end{array}$ \\
\hline
\end{tabular}

TABLE 2: TUS in liver disease, differentials, classical findings, and comparison with chest computed tomography (CT) and chest radiographs (CXR)

Abbreviations: ARDS, acute respiratory distress syndrome; CXR, chest radiograph; CT, computed tomography; COPD, chronic obstructive pulmonary disease; RV, right ventricle; PAOP, pulmonary artery occlusion pressure; PEEP, peak end expiratory pressure; TTE, transthoracic echocardiography; TUS, thoracic ultrasound; LUS, lung ultrasound; TR, tricuspid regurgitation

The presence of pleural effusion or hepatic hydrothorax, underlying consolidation of the lung, liver abscess with rupture, pulmonary embolism, etc., are relevant, urgent situations that must be assessed in critically ill patients with liver disease. The ultrasonography machine should be positioned such that the operator can view the screen with ease, can maneuver the probe, and use a biopsy gun or needle with ease. Ambient light can be adjusted to improve the screen contrast. The clinician then adjusts the depth and gain settings for visualizing the pleura and area of interest. The probe should be held perpendicular to the skin, and the marker should be oriented in the cranial direction. The scanning plane should be adjusted such that the intercostal space (ICS) is central and the ribs frame on either side. This ensures that with an abdominal preset, a longitudinal view of the interspace is obtained, and structures near the skin point to the top of the screen, and deeper structures project to the bottom of the screen. Depth measurements and size of lesions can be measured with calipers [21]. 


\section{Cureus}

\section{Anatomic boundaries}

The three structures identified are the diaphragm, chest wall, and lung. When placed in the intercostal space, the linear probe images from the skin inwards and shows the layers of chest wall muscle, intercostal muscle, hyperechoic pleural line, and lung (Figure 1).

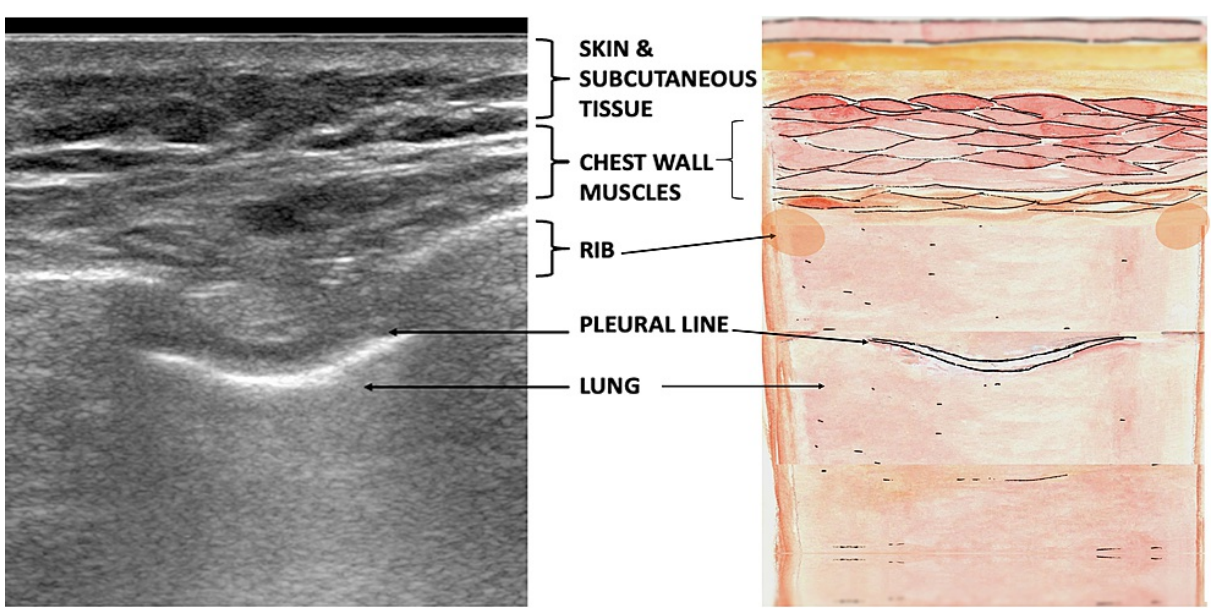

FIGURE 1: Schematic diagram showing the layers of the chest wall

The diaphragm is identified as an echogenic curvilinear structure above the liver on the right and the spleen on the left, which descends caudally with inspiration. The hepatorenal and splenorenal recesses are bounded by the liver and spleen cranially and limited by the respective kidney caudally on either side. The position of the diaphragm may be displaced by a large pleural effusion, paralysis, tense ascites, or morbid obesity $[2,4]$. Figures 2,3 show the appearance of the right and left lung bases on TUS, respectively.
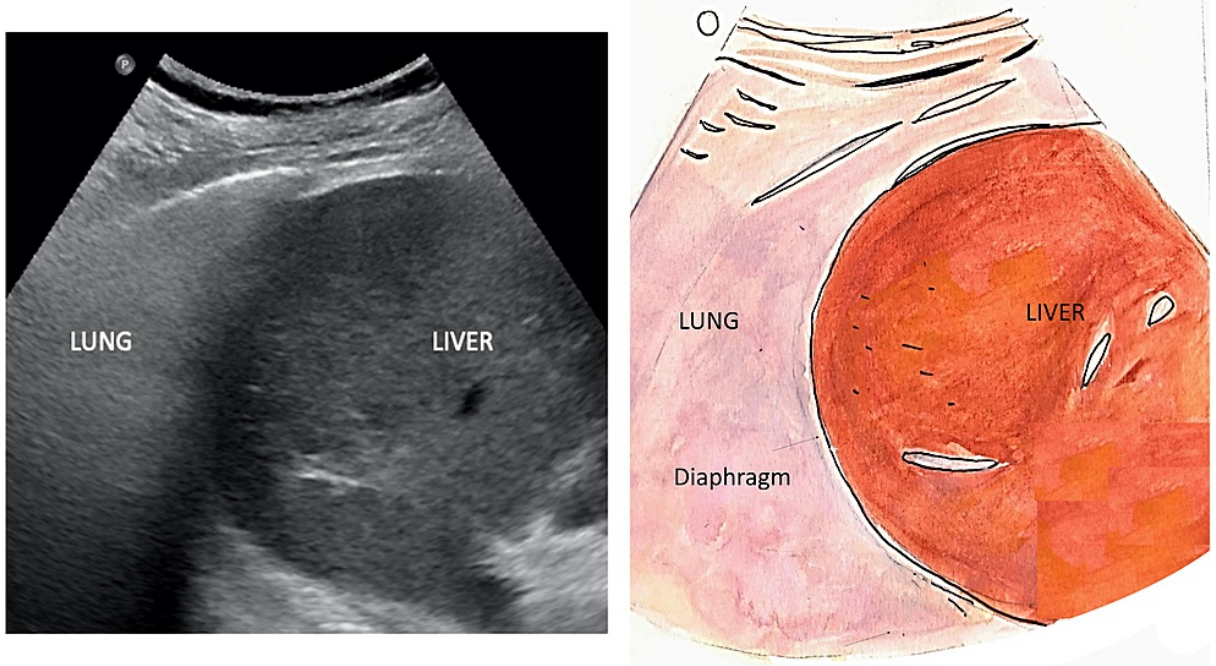

FIGURE 2: Visualization of the right lung base 


\section{Cureus}
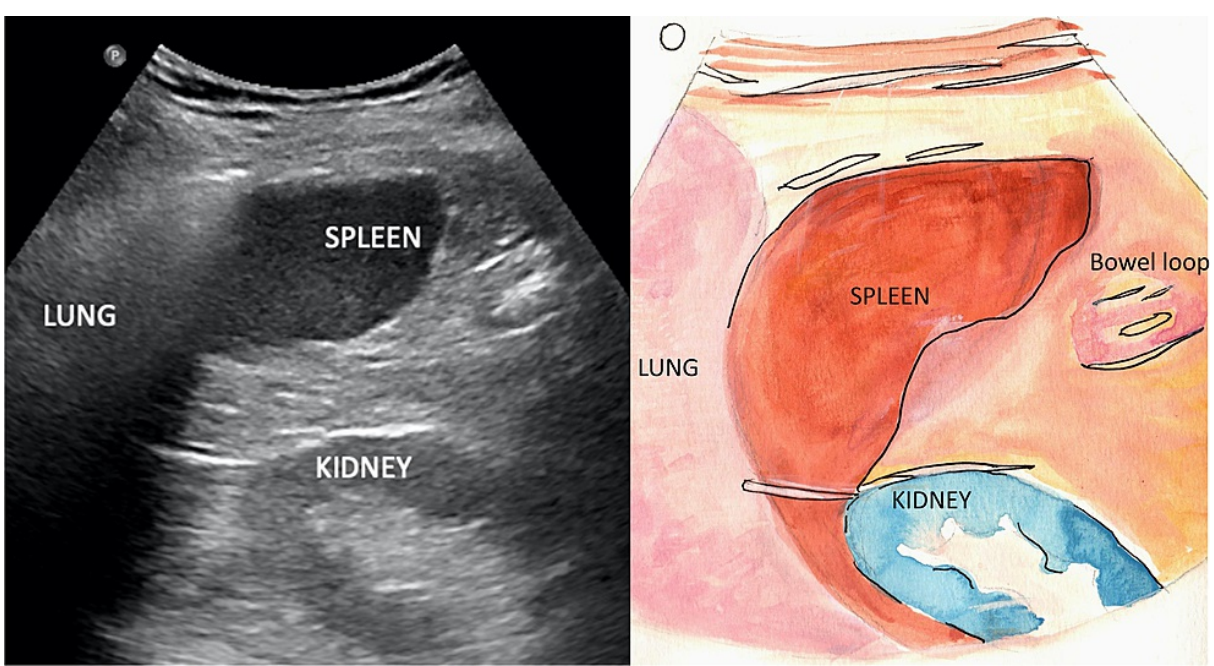

FIGURE 3: Visualization of the left lung base

Lung sliding is the respiration-related movement of the pleural line seen as a shimmering mobile hyperechoic line, which is the interface of the lung with the visceral pleura and the intercostal muscle.

\section{Lung ultrasound score}

Four lung aeration patterns are defined and graded as a semiquantitative global score [18-21].

1. Normal lung aeration: lung sliding present with A-lines and less than two isolated B-lines. A-lines represent normal lung aeration.

2. Moderate loss of lung aeration (B1 lines): multiple well-defined B-lines. B-lines represent interstitial edema (Figure 4).
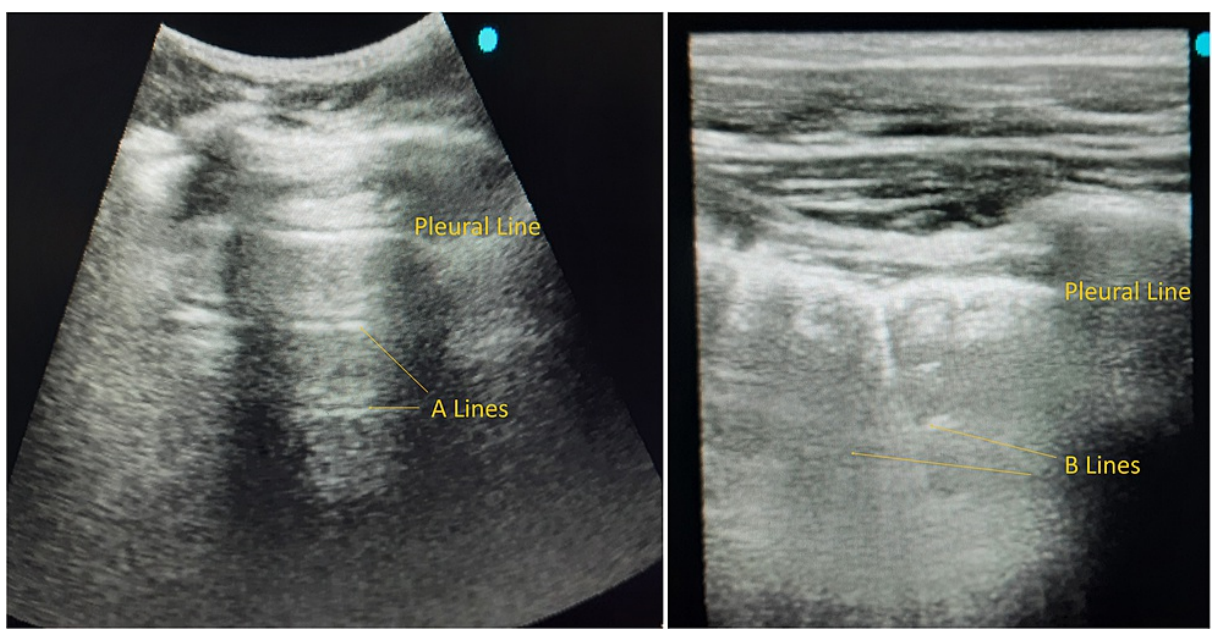

FIGURE 4: The presence of ' $A$ ' lines and ' $B$ ' lines as seen on lung ultrasound

3. Severe loss of lung aeration (B2 lines): multiple coalescent B-Lines

4. Lung consolidation: tissue pattern has a dynamic air bronchogram.

Points are given as per the worst ultrasound pattern observed. Normal $=0 ; \mathrm{B} 1$ lines $=1 ; \mathrm{B} 2$ lines $=2$ and therefore total points are graded between 0 and 36 (Figure 5). 


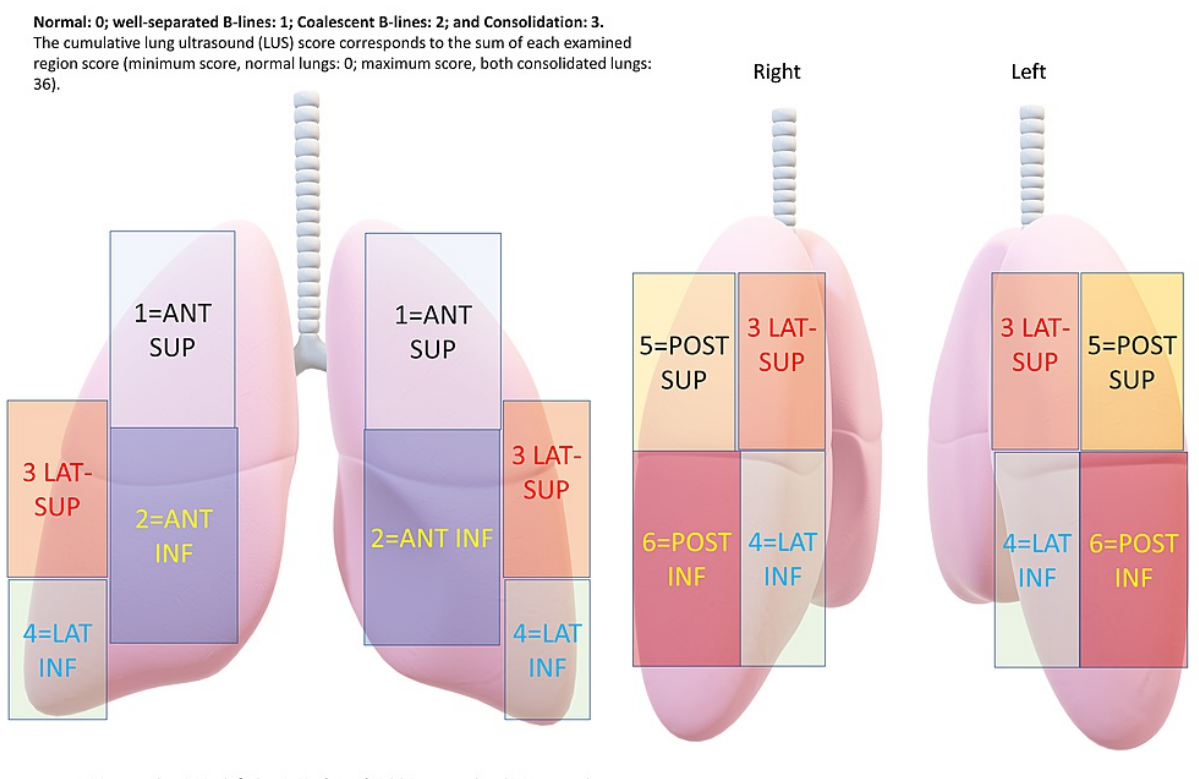

$A N T=$ anterior; INF $=$ inferior; $;$ LAT $=$ lateral; POST $=$ posterior; SUP $=$ superior.

FIGURE 5: Calculation of the lung ultrasound score

A higher elevated lung ultrasound score on admission is associated with a worse outcome as it suggests interstitial edema and is independently associated with a higher Acute Physiologic Assessment and Chronic Health Evaluation II (APACHE II) score and mortality [22,23]. Incorporation of LUS, whether as a scoring system or at least a protocol-based method to sequentially assess fluid status in patients with cirrhosis, is a good bedside tool to maintain fluids status or target ultrafiltration in dialysis.

\section{Scanning technique and patient position}

The scanning technique and patient position for pleural pathologies are like that for imaging of the lung. Stable patients who can sit upright should be imaged in this position, leading forward while resting their elbows on a table in front of them, exposing the back. Arms can be raised above the head to access the anterior and lateral portions of the chest wall. Patients with critical illness or those on mechanical ventilation must be imaged in the supine and semi-upright state with the ipsilateral arm adducted across the chest wall towards the opposite side. To image smaller effusions, the posterior axillary line needs to be exposed to enable a thoracentesis. This is difficult in patients who are mechanically ventilated, and a team member must be stationed to avoid displacement of the endotracheal tube [24].

\section{Pneumothorax}

The diagnosis of pneumothorax and ultrasound-guided thoracostomy tube is most useful at the bedside. The loss of pleural sliding is characteristic of pneumothorax with a few differentials. The lung point is observed at the interface between the pneumothorax (where there is no apposition of the pleura) and the partially deflated lung (where there is still apposition of the two pleural surfaces), where pleural sliding is observed. The lung point refers to the respiration phase varying, the intermittent appearance of lung sliding at a point where sliding disappears at the start of the pneumothorax area [25]. Xirouchaki et al. reported the sensitivity and specificity of LUS as $100 \%$ and $78 \%$ for consolidation, $94 \%$ and $93 \%$ for interstitial syndromes, $75 \%$ and $93 \%$ for pneumothorax, and $100 \%$ and $100 \%$ for pleural effusion [26]. The sensitivity of chest radiograph (CXR) diagnosis was lower: $38 \%$ and $89 \%$ for consolidation, $46 \%$ and $80 \%$ for interstitial syndromes, $0 \%$ and $99 \%$ for pneumothorax, and $65 \%$ and $81 \%$ for pleural effusion. Zanobetti et al. compared the concordance of TUS, chest radiography, and chest computed tomography (CT) scans in 404 mechanically ventilated patients. The performance of TUS was like chest radiography for the identification of pulmonary edema, pneumothorax, and consolidation and was superior for the identification of pleural effusion [27]. Color Doppler can be used to identify blood vessels in the pleura and can be used to avoid bleeding in pleural taps or drain insertions in patients with liver abscesses.

\section{Pleural effusion and hepatic hydrothorax}

Patients with cirrhosis frequently develop hepatic hydrothorax, and reactive pleural effusions develop in patients with liver abscesses. Another scenario is to image synpneumonic effusions in patients or post-liver biopsy bleeding. Patients with pleural tuberculosis or lung masses also develop effusions. Hepatic hydrothorax is characterized by the development of pleural effusion due to diaphragmatic defects, which suck in portal hypertensive ascites due to the negative intrapleural pressure. The majority occur in the right 
hemithorax. A hemothorax is defined as a bloody pleural effusion with a hematocrit exceeding half the value in peripheral blood [28]. TUS was superior to chest radiography for the diagnosis of pleural effusion (93\% versus $47 \%$ ), alveolar consolidation (97\% versus $75 \%$ ), and alveolar-interstitial syndrome (95\% versus 55\%) [29]. Svigals et al. reported that pleural ultrasound had a sensitivity of $69.2 \%$ (95\% CI: $48.2 \%$ to $85.7 \%$ ) and specificity of $90.0 \%$ (95\% CI: $76.3 \%$ to $97.2 \%$ ). Chest CT scan had a sensitivity of $76.9 \%$ (95\% CI: $56.3 \%$ to 91.0\%) and specificity of $65.0 \%$ (95\% CI: $48.3 \%$ to $79.4 \%$ ). CXR had a sensitivity of $61.5 \%$ (95\% CI: $40.6 \%$ to $79.8 \%$ ) and specificity of $60.0 \%$ (95\% CI: $43.3 \%$ to $75.1 \%$ ). Pleural ultrasound appears to be a superior modality to rule in a complex pleural effusion when compared with chest CT scan and CXR [30].

\section{Use of TUS in intensive care practice in a liver ICU}

The use of TUS has changed intensive care practice the world over, with increased application in hepatology and transplant practice. TUS can be applied to guide weaning protocols in patients with liver disease, reduce post-extubation stress [23] and assess the effect of antimicrobial therapy in patients with ventilatorassociated pneumonia, septic shock [31], and recruitment strategies using peak end expiratory pressure (PEEP) in patients on mechanical ventilation [32]. Reduction in LUS score and improvement in consolidation, in conjunction with ventilatory requirement, serum biomarkers of sepsis-like procalcitonin, and hematological scores, can help determine the resolution of pneumonia. We routinely use the daily POCUS round in the ICU to determine the improvement in the LUS score in patients with a critical illness. When clinical parameters, fraction of inspired oxygen $\left(\mathrm{FiO}_{2}\right)$ requirement, sepsis markers and cultures, and LUS score show an improving trend, the patient can be initiated on a de-escalation protocol. Two additional indices are of use in critically ill patients with liver disease, especially ACLF: the oxygenation index and the extravascular lung water (EVLW) index.

Oxygenation index (OI) is a score used in intensive care practice to measure FiO2 and its use in the body. It is calculated using the formula $\mathrm{OI}=\left(\mathrm{FiO}_{2} \times \mathrm{M}_{\mathrm{PAW}}\right) / \mathrm{PaO}_{2}$, where $\mathrm{FiO}_{2}$ refers to the fraction of inspired oxygen in $\%, \mathrm{M}_{\mathrm{PAW}}$ refers to the mean airway pressure in $\mathrm{mmHg}$, and $\mathrm{PaO}_{2}$ refers to the partial pressure of oxygen in arterial blood, in mmHg. The higher the OI, the lower is the needed $\mathrm{FiO}_{2}$ to maintain a higher $\mathrm{PaO}_{2}$.

The EVLW index is the amount of water contained within the lung parenchyma that is outside the pulmonary vasculature. It is usually measured by specific thermodilution techniques, and the use of LUS to help estimate the EVLW is under scrutiny.

Alveolar interstitial syndrome (AIS) can be diagnosed using TUS to detect pulmonary edema, which appears as diffuse B-lines. AIS is seen in several conditions including, but not limited to acute decompensated heart failure, noncardiogenic pulmonary edema, bilateral pneumonia/pneumonitis, and lung cancer [33,34]. Extensive B-Lines reduced functional vital capacity (FVC) and forced expiratory volume in the first second (FEV1) in a study on pre-liver transplant surgical evaluation, and they may be an independent factor in worsening pulmonary function in these patients [35,36]. Extravascular lung water (EVLW) can also be used as an end point in determining fluid status during liver transplantation or cirrhosis with shock in the intensive care unit [37-39]. The recent COVID-19 pandemic expanded the use of POCUS in liver intensive care practice. Peng et al. showed TUS could predict the clinical course and outcome of COVID-19 in an initial study from China [40]. Similar data have been reported by Lichter et al., and the LUS score has gained acceptability with shorter protocol modifications by imaging only the anterior or lateral segments [41]. Figure 5 shows patterns of pneumonia, lung collapse, and pleural effusion in patients with cirrhosis and ascites, which show difficult to interpret radiographs. 


\section{Cureus}
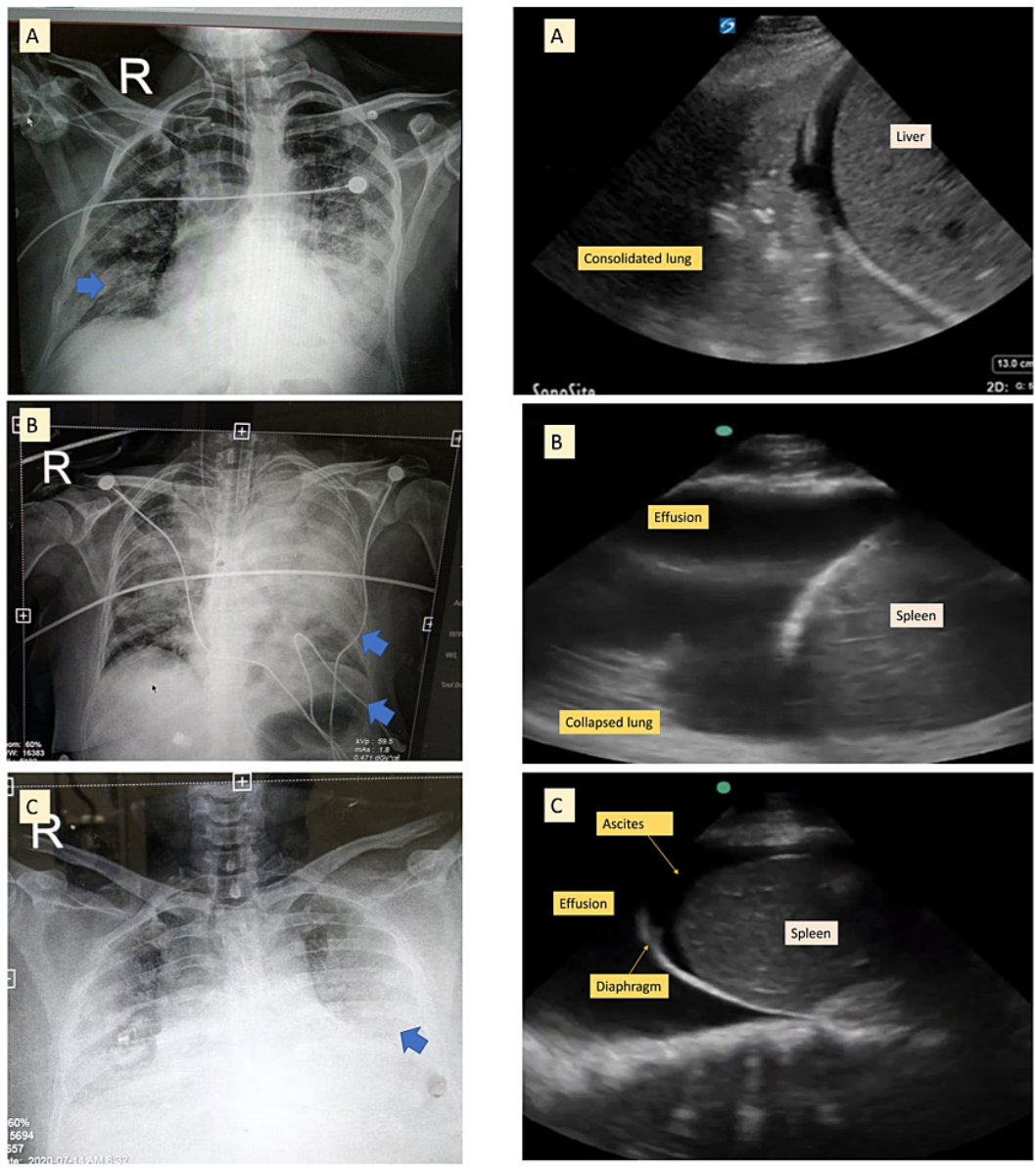

\section{FIGURE 6: Visualization of different pneumonia patterns on chest radiograph in patients with cirrhosis and correct interpretation using lung ultrasound}

TUS simplifies the diagnosis as an iterative point-of-care (POC) tool.

\section{Ultrasound-guided procedures}

A central venous access device is defined as a catheter that has its tip located in the superior vena cava, right atrium (RA), or inferior vena cava (IVC). Central venous catheters include central venous lines (jugular or subclavian), dialysis catheters, and peripherally inserted central lines. These are commonly inserted in patients with cirrhosis and ACLF for venous access or dialysis. The use of the central venous pressure (CVP) to estimate volume status in patients with hepatorenal syndrome is largely abandoned [42]. TUS has limitations as ultrasound resolution decreases with depth. Vascular structures are difficult to identify in morbidly obese patients or those with anasarca. Volume depleted patients with ACLF also have coagulation failure, which may make central venous access difficult, in addition to coagulation failure-related risk. Spencer et al. have suggested rapid central vein assessment (RaCeVA) as a systematic way for ultrasound assessment before central venous catheterization [43]. Thoracentesis and drain insertions and drainage of liver abscesses are frequently done in the ICU using similar techniques. The POCUS of the thorax and bedside echocardiography are complementary techniques in the ICU. We have previously described the method, interpretation, and utility of telecardiology tools to improve time to diagnosis in critically ill patients with liver disease [44].

\section{Pulmonary complications of cirrhosis}

The two pulmonary syndromes in cirrhosis deserve mention here as they are relevant in managing patients with cirrhosis and ACLF who are critically unwell and have a bearing on transplantation outcomes. Hepatopulmonary syndrome (HPS) is caused by impaired pulmonary capillary oxygenation due to the bypass of the alveolar circulation by intrapulmonary vascular dilations (IPVDs). It can be screened at the bedside using an intravenous agitated saline contrast POC echocardiography in tandem with arterial blood gas analysis. HPS is diagnosed if the pulmonary alveolar arterial oxygen gradient $(\mathrm{AaO} 2) \geqslant 15 \mathrm{mmHg}$, or $\geqslant 20$ $\mathrm{mmHg}$ in persons aged $>64$ years [45]. Pulmonary capillaries are normally $<8-15$ microns. If microbubbles 
(>10 microns) appear in the left heart after three-to-six cardiac cycles of injecting the agitated saline in the antecubital vein, it suggests that IPVDs are present, indicating the need for confirmatory tests for HPS [46]. The second pulmonary syndrome is porto-pulmonary hypertension (POPH), diagnosed by right heart characterization, with a resting pulmonary artery pressure (mPAP) $\geqslant 25 \mathrm{mmHg}$. In contrast with $\mathrm{HPS}, \mathrm{POPH}$ is characterized by pulmonary vessel vasoconstriction. POC echocardiography can determine the right ventricular systolic pressure (RVSP) and pulmonary arterial pressure (PAP) by continuous-wave doppler if tricuspid regurgitation (TR) is present. Systolic PAP can be measured by the peak TR velocity jet, and right atrial pressure can be determined by the simplified Bernoulli equation based on the inferior vena cava (IVC) diameter and respiratory variation [47]. Another bedside parameter to judge RA pressure is dynamic IVC measurement. An IVC diameter of $<2.1 \mathrm{~cm}$ that collapses $>50 \%$ with a sniff indicates normal RA pressure of 0-3 mmHg (range: $0-5 \mathrm{mmHg}$ ) and an IVC $>2.1 \mathrm{~cm}$ that collapses $<50 \%$ with a sniff or $<20 \%$ on quiet inspiration suggests a high RA pressure of $15 \mathrm{mmHg}$ (range: $10-20 \mathrm{mmHg}$ ).

\section{Cirrhotic cardiomyopathy}

The use of TUS and POC echocardiography is now complimentary. Patients with critical illnesses like variceal bleed, hepatorenal syndrome (HRS), and sepsis frequently have underlying cirrhotic cardiomyopathy (CCM), which is seen in 30-50\% of individuals. CCM may be asymptomatic and may be first diagnosed on transplant workup or may be diagnosed for the first time in case of acute stress like sepsis, bleeding, or interventions like transjugular intrahepatic portosystemic shunt [48]. These situations, which require the cirrhotic heart to increase the cardiac output, often precipitate heart failure, indicating there is a limited cardiac reserve. This has important implications in the management of critically ill patients with cirrhosis at the onset of shock, as they might not respond to a fluid challenge and require early use of vasopressors. Hence combing basic echocardiography, TUS, and IVC dynamics, we can detect pulmonary and cardiac issues in patients with liver disease, determine the dose of fluids for resuscitation, initiate timely vasopressors, and determine the dose of dialysis and safety of albumin or blood components in patients with volume overload.

\section{Limitations of POCUS of the lung and heart}

TUS has limitations related to operator and patient-dependent factors. TUS requires correct clinical skills and interpretation of LUS findings, which requires short training of operators. Easily identifiable LUS signs, as described in this review, can be taught with brief training videos, like ruling out pneumothorax or diagnosing a pleural effusion [49]. In patients with cirrhosis, the presence of ascites and coagulopathy often makes movement and guided procedures difficult. Obesity, the presence of subcutaneous emphysema, and large dressings make examination and propagation of the ultrasound beam difficult in post-operative patients and those on mechanical ventilation [50]. However, in the hands of an experienced operator, the LUS gives better real-time information in critically unwell patients as a part of the POCUS examination for multiple organ systems. LUS cannot detect lung hyperinflation due to increased thoracic pressures. Tense ascites make it difficult to find a suitable window for IVC dimension estimation, and a poor echocardiographic window makes it difficult to assess the heart. In patients on high PEEP, there is increased right ventricle (RV) pressure which causes a bulge of the RV into the left ventricle. Also, a $5 \mathrm{~cm}$ increase in PEEP will be associated with a $2.5 \mathrm{~cm} \mathrm{H} 2 \mathrm{O}$ increase in CVP [51].

\section{Conclusions}

POCUS is increasingly used in critically ill patients with cirrhosis and liver failure for diagnosing pleural and pulmonary parenchymal pathology, guide ventilatory pressures, and diagnose extubation failures in patients on mechanical ventilation. The use of POCUS has greatly improved our diagnostic and therapeutic finesse, enabled the safe introduction of drains, evidence-based use of anticoagulation, diuretics, and antibiotics, and is increasingly accepted in daily intensive care practice in the liver intensive care and transplantation units. We could better titrate ventilatory support and guide weaning protocols, thoracentesis, drain placement, and central venous access, which are central to the management of critically ill patients with liver disease. The use of basic echocardiography to assess volume status, diagnose systolic and diastolic dysfunction, and screen liver-specific syndromes like hepatopulmonary syndromes and porto-pulmonary hypertension is of increased relevance. The combined use of POC TUS and echocardiography has greatly improved care for critically ill patients with liver disease and liver transplantation.

\section{Additional Information \\ Disclosures}

Conflicts of interest: In compliance with the ICMJE uniform disclosure form, all authors declare the following: Payment/services info: All authors have declared that no financial support was received from any organization for the submitted work. Financial relationships: All authors have declared that they have no financial relationships at present or within the previous three years with any organizations that might have an interest in the submitted work. Other relationships: All authors have declared that there are no other relationships or activities that could appear to have influenced the submitted work.

\section{Acknowledgements}


The support of Dr. Sekar Loganathan MD, Senior Fellow, Department of Anesthesia and Intensive Care, and Ms. Harpreet Kaur, MSc., Senior Research Fellow in the Department of Hepatology, Postgraduate Institute of Medical Education and Research, Chandigarh, India, in the preparation of this manuscript, is acknowledged. The manuscript is partially supported by a research grant awarded to MP by the Department of Health Research, Indian Council of Medical Research, GIA/2019/000281/PRCGIA.

\section{References}

1. Volpicelli G, Elbarbary M, Blaivas M, et al.: International evidence-based recommendations for point-of-care lung ultrasound. Intensive Care Med. 2012, 38:577-91. 10.1007/s00134-012-2513-4

2. Bataille B, Riu B, Ferre F, et al.: Integrated use of bedside lung ultrasound and echocardiography in acute respiratory failure: a prospective observational study in ICU. Chest. 2014, 146:1586-93. 10.1378/chest.140681

3. Alrajhi K, Woo MY, Vaillancourt C: Test characteristics of ultrasonography for the detection of pneumothorax: a systematic review and meta-analysis. Chest. 2012, 141:703-8. 10.1378/chest.11-0131

4. Cecconi M, De Backer D, Antonelli M, et al.: Consensus on circulatory shock and hemodynamic monitoring. Task force of the European Society of Intensive Care Medicine. Intensive Care Med. 2014, 40:1795-815. 10.1007/s00134-014-3525-z

5. Llamas-Álvarez AM, Tenza-Lozano EM, Latour-Pérez J: Accuracy of lung ultrasonography in the diagnosis of pneumonia in adults: systematic review and meta-analysis. Chest. 2017, 151:374-82. 10.1016/j.chest.2016.10.039

6. Chiumello D, Umbrello M, Sferrazza Papa GF, et al.: Global and regional diagnostic accuracy of lung ultrasound compared to CT in patients with acute respiratory distress syndrome. Crit Care Med. 2019, 47:1599-606. 10.1097/CCM.0000000000003971

7. Bouhemad B, Brisson H, Le-Guen M, Arbelot C, Lu Q, Rouby JJ: Bedside ultrasound assessment of positive end-expiratory pressure-induced lung recruitment. Am J Respir Crit Care Med. 2011, 183:341-7. 10.1164/rccm.201003-03690C

8. Staub LJ, Biscaro RRM, Maurici R: Accuracy and applications of lung ultrasound to diagnose ventilatorassociated pneumonia: a systematic review. J Intensive Care Med. 2018, 33:447-55. 10.1177/0885066617737756

9. Fields JM, Davis J, Girson L, et al.: Transthoracic echocardiography for diagnosing pulmonary embolism: a systematic review and meta-analysis. J Am Soc Echocardiogr. 2017, 30:714-723.e4. 10.1016/j.echo.2017.03.004

10. Mojoli F, Bouhemad B, Mongodi S, Lichtenstein D: Lung ultrasound for critically ill patients . Am J Respir Crit Care Med. 2019, 199:701-14. 10.1164/rccm.201802-0236CI

11. Lepri G, Orlandi M, Lazzeri C, et al.: The emerging role of lung ultrasound in COVID-19 pneumonia . Eur J Rheumatol. 2020, 7:S129-33. 10.5152/eurirheum.2020.2063

12. Smith MJ, Hayward SA, Innes SM, Miller ASC: Point-of-care lung ultrasound in patients with COVID-19 - a narrative review. Anaesthesia. 2020, 75:1096-104. 10.1111/anae.15082

13. Kulkarni AV, Kumar P, Tevethia HV, et al.: Systematic review with meta-analysis: liver manifestations and outcomes in COVID-19. Aliment Pharmacol Ther. 2020, 52:584-99. 10.1111/apt.15916

14. Vetrugno L, Bove T, Orso D, et al.: Our Italian experience using lung ultrasound for identification, grading and serial follow-up of severity of lung involvement for management of patients with COVID-19. Echocardiography. 2020, 37:625-7. 10.1111/echo.14664

15. Lichtenstein DA: Lung ultrasound in the critically ill . Ann Intensive Care. 2014, 4:1. 10.1186/2110-5820-4-1

16. Blaivas M, Lyon M, Duggal S: A prospective comparison of supine chest radiography and bedside ultrasound for the diagnosis of traumatic pneumothorax. Acad Emerg Med. 2005, 12:844-9. 10.1197/j.aem.2005.05.005

17. Reissig A, Copetti R, Mathis G, et al.: Lung ultrasound in the diagnosis and follow-up of communityacquired pneumonia: a prospective, multicenter, diagnostic accuracy study. Chest. 2012, 142:965-72. 10.1378/chest.12-0364

18. Copetti R, Soldati G, Copetti P: Chest sonography: a useful tool to differentiate acute cardiogenic pulmonary edema from acute respiratory distress syndrome. Cardiovasc Ultrasound. 2008, 6:16. 10.1186/1476-7120-616

19. Lichtenstein DA, Mezière GA, Lagoueyte JF, Biderman P, Goldstein I, Gepner A: A-lines and B-lines: lung ultrasound as a bedside tool for predicting pulmonary artery occlusion pressure in the critically ill. Chest. 2009, 136:1014-20. 10.1378/chest.09-0001

20. Platz E, Merz AA, Jhund PS, Vazir A, Campbell R, McMurray JJ: Dynamic changes and prognostic value of pulmonary congestion by lung ultrasound in acute and chronic heart failure: a systematic review. Eur J Heart Fail. 2017, 19:1154-63. 10.1002/ejhf.839

21. Lichtenstein DA: BLUE-protocol and FALLS-protocol: two applications of lung ultrasound in the critically ill. Chest. 2015, 147:1659-70. 10.1378/chest.14-1313

22. Yin W, Zou T, Qin Y, et al.: Poor lung ultrasound score in shock patients admitted to the ICU is associated with worse outcome. BMC Pulm Med. 2019, 19:1. 10.1186/s12890-018-0755-9

23. Soummer A, Perbet S, Brisson H, et al.: Ultrasound assessment of lung aeration loss during a successful weaning trial predicts postextubation distress*. Crit Care Med. 2012, 40:2064-72. 10.1097/CCM.0b013e31824e68ae

24. Buessler A, Chouihed T, Duarte K, et al.: Accuracy of several lung ultrasound methods for the diagnosis of acute heart failure in the ED: a multicenter prospective study. Chest. 2020, 157:99-110. 10.1016/j.chest.2019.07.017

25. Miraglia R, Maruzzelli L, Piazza M, et al.: Real-time ultrasound-guided placement of a pigtail catheter in supine position for draining pleural effusion in pediatric patients who have undergone liver transplantation. J Clin Ultrasound. 2016, 44:284-9. 10.1002/jcu.22294

26. Xirouchaki N, Magkanas E, Vaporidi K, et al.: Lung ultrasound in critically ill patients: comparison with bedside chest radiography. Intensive Care Med. 2011, 37:1488-93. 10.1007/s00134-011-2317-y 
27. Zanobetti M, Scorpiniti M, Gigli C, et al.: Point-of-care ultrasonography for evaluation of acute dyspnea in the ED. Chest. 2017, 151:1295-301. 10.1016/j.chest.2017.02.003

28. Broderick SR: Hemothorax: etiology, diagnosis, and management. Thorac Surg Clin. 2013, 23:89-96. 10.1016/j.thorsurg.2012.10.003

29. Brogi E, Gargani L, Bignami E, Barbariol F, Marra A, Forfori F, Vetrugno L: Thoracic ultrasound for pleural effusion in the intensive care unit: a narrative review from diagnosis to treatment. Crit Care. 2017, 21:325. 10.1186/s13054-017-1897-5

30. Svigals PZ, Chopra A, Ravenel JG, Nietert PJ, Huggins JT: The accuracy of pleural ultrasonography in diagnosing complicated parapneumonic pleural effusions. Thorax. 2017, 72:94-5. 10.1136/thoraxjnl-2016208904

31. Caltabeloti F, Monsel A, Arbelot C, et al.: Early fluid loading in acute respiratory distress syndrome with septic shock deteriorates lung aeration without impairing arterial oxygenation: a lung ultrasound observational study. Crit Care. 2014, 18:R91. 10.1186/cc13859

32. Russell FM, Ehrman RR, Cosby K, Ansari A, Tseeng S, Christain E, Bailitz J: Diagnosing acute heart failure in patients with undifferentiated dyspnea: a lung and cardiac ultrasound (LuCUS) protocol. Acad Emerg Med. 2015, 22:182-91. 10.1111/acem.12570

33. Volpicelli G, Caramello V, Cardinale L, Mussa A, Bar F, Frascisco MF: Bedside ultrasound of the lung for the monitoring of acute decompensated heart failure. Am J Emerg Med. 2008, 26:585-91. 10.1016/j.ajem.2007.09.014

34. Lichtenstein D, Mezière G: A lung ultrasound sign allowing bedside distinction between pulmonary edema and COPD: the comet-tail artifact. Intensive Care Med. 1998, 24:1331-4. 10.1007/s001340050771

35. Cibinel GA, Casoli G, Elia F, Padoan M, Pivetta E, Lupia E, Goffi A: Diagnostic accuracy and reproducibility of pleural and lung ultrasound in discriminating cardiogenic causes of acute dyspnea in the emergency department. Intern Emerg Med. 2012, 7:65-70. 10.1007/s11739-011-0709-1

36. Osni Leão Perin P, de Fátma Ferreira Santana Boin I, Oliveira da Silva AM, Chueiri Neto F, Martins LC: Lung ultrasound and pulmonary function test in cirrhotic patients. Transplant Proc. 2017, 49:824-8. 10.1016/j.transproceed.2017.01.046

37. Theerawit P, Touman N, Sutherasan Y, Kiatboonsri S: Transthoracic ultrasound assessment of B-lines for identifying the increment of extravascular lung water in shock patients requiring fluid resuscitation. Indian J Crit Care Med. 2014, 18:195-9. 10.4103/0972-5229.130569

38. Sussman NL, Kochar R, Fallon MB: Pulmonary complications in cirrhosis . Curr Opin Organ Transplant. 2011, 16:281-8. 10.1097/MOT.0b013e32834664df

39. Singh C, Sager JS: Pulmonary complications of cirrhosis. Med Clin North Am. 2009, 93:871-83. 10.1016/j.mcna.2009.03.006

40. Peng QY, Wang XT, Zhang LN; Chinese Critical Care Ultrasound Study Group (CCUSG): Findings of lung ultrasonography of novel corona virus pneumonia during the 2019-2020 epidemic. Intensive Care Med. 2020, 46:849-50. 10.1007/s00134-020-05996-6

41. Lichter Y, Topilsky Y, Taieb P, et al.: Lung ultrasound predicts clinical course and outcomes in COVID-19 patients. Intensive Care Med. 2020, 46:1873-8. 10.1007/s00134-020-06212-1

42. Premkumar M, Rangegowda D, Kajal K, Khumuckham JS: Noninvasive estimation of intravascular volume status in cirrhosis by dynamic size and collapsibility indices of the inferior vena cava using bedside echocardiography. JGH Open. 2019, 3:322-8. 10.1002/jgh3.12166

43. Spencer TR, Pittiruti M: Rapid central vein assessment (RaCeVA): a systematic, standardized approach for ultrasound assessment before central venous catheterization. J Vasc Access. 2019, 20:239-4. $10.1177 / 1129729818804718$

44. Premkumar M, Kajal K, Kulkarni AV, Gupta A, Divyaveer S: Point-of-care echocardiography and hemodynamic monitoring in cirrhosis and acute-on-chronic liver failure in the COVID-19 era. J Intensive Care Med. 2021, 36:511-23. 10.1177/0885066620988281

45. Krowka MJ, Fallon MB, Kawut SM, et al.: International Liver Transplant Society practice guidelines: diagnosis and management of hepatopulmonary syndrome and portopulmonary hypertension. Transplantation. 2016, 100:1440-52. 10.1097/TP.0000000000001229

46. Fussner LA, Iyer VN, Cartin-Ceba R, Lin G, Watt KD, Krowka MJ: Intrapulmonary vascular dilatations are common in portopulmonary hypertension and may be associated with decreased survival. Liver Transpl. 2015, 21:1355-64. 10.1002/1t.24198

47. Krishnan S, Kuhl T, Ahmed W, Togashi K, Ueda K: Efficacy of an online education program for ultrasound diagnosis of pneumothorax. Anesthesiology. 2013, 118:715-21. 10.1097/ALN.0b013e31827f0979

48. Premkumar M, Rangegowda D, Vyas T, et al.: Carvedilol combined with ivabradine improves left ventricular diastolic dysfunction, clinical progression, and survival in cirrhosis. J Clin Gastroenterol. 2020, 54:561-8. 10.1097/MCG.0000000000001219

49. Mendizabal M, Goldberg DS, Piñero F, et al.: Isolated intrapulmonary vascular dilatations and the risk of developing hepatopulmonary syndrome in liver transplant candidates. Ann Hepatol. 2017, 16:548-54. 10.5604/01.3001.0010.0289

50. Vignon P, Dugard A, Abraham J, et al.: Focused training for goal-oriented hand-held echocardiography performed by noncardiologist residents in the intensive care unit. Intensive Care Med. 2007, 33:1795-9. 10.1007/s00134-007-0742-8

51. Cherpanath TG, Lagrand WK, Binnekade JM, Schneider AJ, Schultz MJ, Groeneveld JA: Impact of positive end-expiratory pressure on thermodilution-derived right ventricular parameters in mechanically ventilated critically ill patients. J Cardiothorac Vasc Anesth. 2016, 30:632-8. 10.1053/j.jvca.2015.09.010 